\title{
Effects of gonadotropins in female infertility associated with depression
}

\author{
Roxana Mihaela Barbu, Cristina-Maria Gavrilescu, Bogdan Stana, \\ Răducu Ionuț Popescu, Pohaci-Antonesei Catalin, Walther Bild
}

\begin{abstract}
Roxana Mihaela Barbu - MD, PhD, Department of Physiology, University of Medicine and Pharmacy „Grigore T. Popa”, Iași, Specialist in Clinical Pharmacology, Romania

Cristina-Maria Gavrilescu - Lecturer, MD, PhD, „Grigore T. Popa” University of Medicine and Pharmacy, Iași, Ist Medical Department, Iași, Romania, senior in Internal Medicine, specialist în Geriatrics, specialist în Clinical Pharmacology

Bogdan Stana - Lecturer, MD, PhD, „Grigore T. Popa” University of Medicine and Pharmacy, Iaşi, Specialist in Pediatrics, Romania.

Răducu Ionuț Popescu - MD, PhD, Department of Physiology, University of Medicine and Pharmacy „Grigore T. Popa”, Iași, Romania.

Pohaci-Antonesei Catalin - MD, PhD, Department of Physiology, University of Medicine and Pharmacy „Grigore T. Popa”, Iași, Specialist in Occupational Medicine, Romania.

Walther Bild - MD, PhD, Professor Department of Physiology, University of Medicine and Pharmacy „Grigore T. Popa”, Iași, Romania.
\end{abstract}

\begin{abstract}
Introduction: The relationship between LH and FSH changes and mental health is not clear yet, but may be independent of a strict diagnosis of infertility. Ongoing research has suggested that testosterone levels may play a role in brain development, which could provide a possible explanation for this association. Healthcare providers caring for women with infertility need to be aware that their patients may face many challenges when faced with infertility, such as depression. An in-depth assessment of the psychiatric needs of patients with infertility is crucial to provide specialized care to this category of patients. The aim of the study was to observe the possible implications of FSH and LH hormones in infertility and associated depression through studying the hormone levels in two Swiss mice groups and to compare these findings to the current literature. Materials and Methods: We used 20 Swiss nulliparous female mice and 15 Swiss multiparous female mice and we measured the luteinizing hormone and follicle-stimulating hormone in each group. Results: We observed a significant increase in mean LH and FSH in the multiparous group compared to the nulliparous group. In conclusion, significant differences in LH and FSH în the multiparous group compared to the nulliparous group and the presence of variations between the two groups of the studied mice
\end{abstract}



suggest that a decrease in LH and FSH in nulliparous females could cause infertility that could also be associated with depression.

\section{KEYWORDS:}

\section{Follicle-stimulating hormone, luteinizing hormone, infertility, depression.}

\section{INTRODUCTION}

Starting from the hypothesis that the human body produces two types of gonadotropin, such as follicle-stimulating hormone (FSH) and luteinizing hormone (LH), synthesized by the pituitary gland, gonadotropins trigger the production of other sex hormones (1). Therefore, gonadotropins play an important role in the production of eggs and sperm, as well as in physical changes in men and women, such as voice, muscles, hair and breast development (2). Human

menopausal gonadotropin (hMG) and recombinant follicle-stimulating hormone $(\mathrm{rFSH})$ are drugs useful in the treatment of infertility, as hMG contains natural FSH and LH, purified from postmenopausal woman's urine (3). After menopause, the woman produces increased amounts of gonadotropin, which is excreted in the urine. rFSH is genetically synthesized in the laboratory. Human chorionic gonadotropin (hCG) is similar to LH; contains equal amounts of LH and FSH. These hormones play an important role in egg production (4).

Based on the fact that studies using animal models have provided important perspectives on the pathogenesis, mechanisms and new therapeutic approaches of human diseases, in this study we provide an overview of the existing evidence for physiological, behavioral, cellular and molecular actions of luteinizing hormone and folliculostimulant hormone in the context of neurotransmission control in the circuits of the central nervous system that regulates mood and motivation and discusses the pathology that leads to mental disorders such as depression in women diagnosed with infertility $(5,6)$.

Infertility affects $15 \%$ of couples and is defined as the absence of pregnancy after a trial period of 1 year, during which the couple has regular and unprotected sex (7). The causes of infertility in women have changed dramatically in recent years with the emergence of new risk factors closely related to the polluted environment in which we live, but also with mental illness, such as depression, which can be a fairly important risk factor in the process of female reproduction. In proportion of $25 \%$ the causes of infertility are related to ovulation, a category that includes women with polycystic ovaries, those who face premature ovarian failure or luteal phase deficiency, but also women who suffer from hormonal disorders, especially related to FSH and LH secretion, hormones that are responsible for the ovulation process $(8,9)$.

There are strong correlations between infertility and mental health disorders. Depression rates have been increased in many studies included in this very sensitive female subject, while other studies have noted significant increases in diagnosis of anxiety or psychosocial distress in women diagnosed with infertility $(10,11)$. Many studies evaluating mental health are limited by the fact that psychiatric disorders can be underdiagnosed or treated on an outpatient basis and therefore excluded from evaluation when hospitalizations are used as inclusion criteria $(12,13)$. Based on research, most patients with subsequent mental health 
s

challenges appear to have a diagnosis of depression (14).

LH is an important component of the menstrual cycle. It works in conjunction with follicular stimulation hormone (FSH), which is another gonadotropin produced by the pituitary gland. FSH stimulates the ovarian follicles, causing the development of oocytes. FSH also supports the production of estrogen in the follicle $(15,16)$. The increase in estrogen causes the pituitary gland to stop producing FSH and start producing more LH. The increase in $\mathrm{LH}$ production causes the release of the oocyte from the ovary, a process called ovulation. In the empty follicle, the cells proliferate, transforming into the luteal body, the structure that releases progesterone, a hormone that prepares the mucosa for the implantation of the fertilized egg, necessary to preserve the pregnancy (17). If pregnancy does not occur, progesterone levels drop and the cycle resumes, which could be a cause of female infertility (18).

Comparing the two sexes, in women, luteinizing hormone and follicle-stimulating hormone are needed for egg production. Women with low levels of this type of hormone, who do not ovulate, can be injected with hMG and $\mathrm{rFSH}$ in the first part of the menstrual cycle for 12 days $(19,20)$. If this stimulates follicular maturation, the ovary will be able to ovulate. Subsequently, a dose of human chorionic gonadotropin (hCG) will be used to stimulate ovulation (21).

On the other hand, in men with low levels of testosterone and FSH, LH stimulates testosterone production, and FSH is involved in sperm formation. If FSH and LH levels are dosed, and the results suggest that there are abnormal levels that prevent sperm from forming, these gonadotropins may be prescribed to stimulate sperm production (22).
Thus, hCG needs to be injected three times a week, until normal serum testosterone levels are reached (this can take 4 to 6 months). Treatments continue with injections of hCG twice a week and hMG or FSH three times a week until sperm levels return to normal (23). In this context, the aim of the presentation was to compare the values of hormonal doses for LH and FSH in nulliparous and multiparous female mice and to identify the etiology of depression in multiparous, starting from the idea that fluctuating levels of the two reproductive hormones trigger a psychiatric affective pathology.

\section{MATERIAL AND METHOD Experimental animals used}

Swiss mice, adult females, of which 20 nulliparous and 15 multiparous weighing 18$20 \mathrm{~g}$, were used for all experiments. The animals were housed in individual cages at a temperature of $21 \pm 2^{\circ} \mathrm{C}$, nictemeral cycle of 12-12 hours., with food and water at their discretion. All animals were kept in similar environmental and feeding conditions.

\section{Blood collection and testing}

In the morning, between 8 and 9 am, Swiss mice were weighed, anesthetized with inhaled isoflurane, and blood samples were collected by taking blood from the left ventricle directly into the vacutainer, approximately $1.5-2 \mathrm{ml} /$ mouse, then placed. immediately on ice. The serum was isolated by centrifugation at $2500 x$ g for $15 \mathrm{~min}$. The serum was aliquoted and frozen at $-20 \circ \mathrm{C}$ until analysis. Luteinizing hormone and follicle-stimulating hormone were analyzed by ELISA (mouse kit luteinizing hormone, cat. RTC009R, BioVendor, Czech Republic; folliclestimulating hormone kit for mice, cat. RTC006R, BioVendor, Czech Republic).

The wells were coated with anti-LH antibody and anti-FSH antibody. An unknown amount 


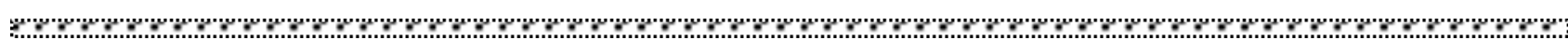
of hormone present in the sample competes stimulating hormone (FSH) is made by the with a hormone-radish peroxidase (HRP) conjugate for binding to the coated antibody. Each serum sample was analyzed in duplicate with each of the four ELISA kits according to the manufacturer's instructions. The absorbance at each test was read at a wavelength of $450 \mathrm{~nm}$ with a plate reader (State Fax 303 Plus, Awarness Technology Inc, USA). Based on the standard curves on each plate, the hormonal concentration of each hormone was determined for each mouse in the two groups studied.

\section{Biochemical estimates}

The determination of $\mathrm{LH}$ in female Swiss mice was performed by the sandwich ELISA method, using biotin-labelled antibody. Luteinizing hormone (LH) is produced in both men and women in the anterior pituitary gland in response to luteinizing hormonereleasing hormone (LH-RH or Gn-RH), which is released by the hypothalamus. The calibration range of $\mathrm{LH}$ is between $0.313 \mathrm{pg} /$ $\mathrm{ml}-10 \mathrm{pg} / \mathrm{ml}$, and the limit of detection of $\mathrm{LH}$ in the body is equal to $10 \mathrm{pg} / \mathrm{ml}$.

FSH measument in female Swiss mice was performed by the sandwich ELISA method, using biotin-labelled antibody. Follicle pituitary gland in the brain. The calibration range of progesterone is between $0.34 \mathrm{pg}$. / $\mathrm{ml}$ - $10 \mathrm{pg} . / \mathrm{ml}$, and the limit of detection of oestradiol in the body is equal to $10 \mathrm{pg}$. $/ \mathrm{ml}$.

Data Analysis. We used single variance analysis (ANOVA). Results are expressed as mean \pm SEM. $F$ values for which $P<0.05$ were considered statistically significant.

\section{RESULTS}

In this study we demonstrated the hypothesis that fluctuations in reproductive hormone levels in women can trigger infertility associated with depression, depending on the pathological effects and values of sex steroid hormones such as luteinizing and folliculostimulating hormone, using experimental animals - Swiss mice, nulliparous and multiparous females sing between $18 \mathrm{~g}-25 \mathrm{~g}$. We analyzed two groups of animals, thus, a group of 20 nulliparous female mice and the second group of 15 multiparous female mice. For the two groups, a comparison was made between the values of luteinizing and folliculostimulating hormone concentrations for each nulliparous and multiparous female mouse.

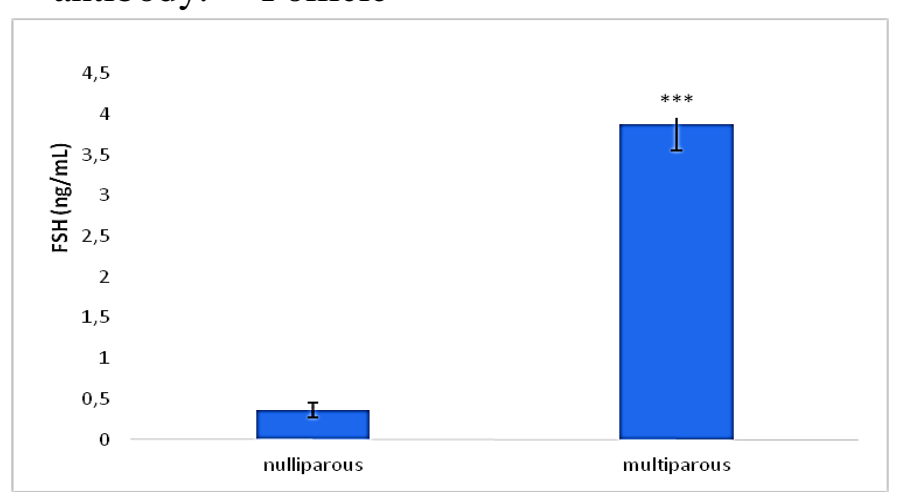

Fig.1. Mean values in nulliparous and multiparous female mice for the levels FSH. The values are mean \pm S.E.M. ( $n=20$ in nulliparous group and $n=15$ in multiparous ), $* * * p<0.0001$ vs. nulliparous group.

Figure 1 represents a significant increase in the analysis of mean values in the group of multiparous female mice compared to nulliparous ones, in the analysis of follicle- 

significantly higher in the group of nulliparous ones.

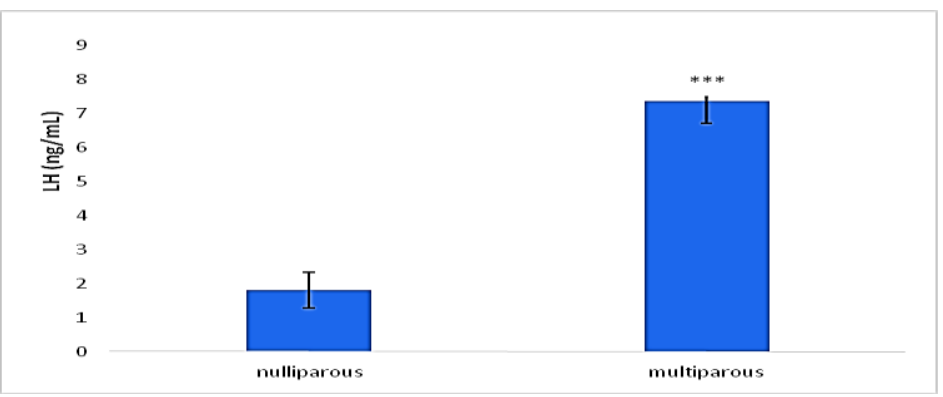

Fig. 2. Mean values in nulliparous and multiparous female mice for the levels of LH. The values are mean \pm S.E.M. ( $n=20$ in nulliparous group and $n=15$ in multiparous $), * * * p<0.0001$ vs. nulliparous group.

Figure 2 represents a significant increase in the analysis of mean values in the group of multiparous female mice compared to nulliparous ones, in the analysis of luteinizing hormone. Thus, the LH level is significantly increased in the group of multiparous female mice, compared to nulliparous ones.

Regarding the group differences between the group of nulliparous mice and multiparous mice, we observed that in multiparous female mice, the values of FSH and LH values have a significant increase compared to the average values in nulliparous female mice.

Our results are consistent with the observed epidemiological relationship between menstrual cycles and the type of female mice used, nulliparous and multiparous. However, based on the analysis performed, it was observed that the multiparous female does not suffer from so many episodes of depression compared to the nulliparous female (due to infertility).

\section{DISCUSSION}

The present study investigated the relationship between the effects of $\mathrm{LH}$ and FSH on non-reproductive depression, the possible cause of infertility, compared to reproductive depression, using nulliparous and multiparous female mice, in which the two hormones were dosed, thus identifying hormonal differences. found in the two study groups.

Female infertility and associated reproductive disorders can have ramifications for women beyond reproductive health. An analysis of the publications shows that women with infertility had higher rates of psychiatric disorders than the general population (24). The data are contradictory as to whether infertile women are at increased risk for depression. A widespread diagnosis of infertility has not been clearly associated with an increased risk of cardiovascular disease or metabolic dysfunction, but women with depression-related infertility appear to be more likely to develop cardiovascular disease and mental disorders than women of childbearing age in the general population (25).

There is growing evidence that proves that women with a diagnosis of infertility associated with depression may be more likely to develop other health problems that may not occur simultaneously with their infertility (26). Although we cannot definitively say that infertility always causes health problems, such as psychiatric disorders or other somatic problems, published studies show that infertility is not an isolated 
diagnosis, but rather part of a complex interaction of risk factors that can had an overall impact on women's health (27). This study suggests that women with infertility may be at higher risk of developing health problems outside of their immediate infertility. The present research demonstrates the need to provide truly comprehensive care to women diagnosed with infertility, which may include depression, as a very important risk factor. Additional screening tests, lifestyle changes and treatment seem justified in this category of women. Infertility is a complex healthcare issue, but clarifying an accurate diagnosis for a patient's infertility, when possible, helps stratifying the patients at risk for direct counseling with impact on somatic health.

\section{CONCLUSIONS}

This study shows that, depending on the period in which the woman is, before or after pregnancy, in the two groups of nulliparous and multiparous female mice, the hormonal concentrations for LH and FSH have very different values from physiological to pathological. We demonstrated a significant increase between the parameters of LH and FSH values in the two groups of mice studied.

Thus, we have a significant increase between the parameters of reproductive hormone fluctuations for $\mathrm{LH}$ and FSH, between the groups of multiparous and nulliparous female mice, which could trigger the affective hormonal disorder in some women with depression.

The study found that changes in multiple biological systems, such as the immune system, the hypothalamic-pituitary-adrenal cortex, and lactogenic hormones contribute to the pathophysiology of infertility depression.

Female infertility and its associated diagnosis have general implications for human health. Beyond addressing patients' immediate reproductive needs, healthcare professionals need to be aware of the wider health impact of specific causes of infertility in order to provide accurate advice on long-term risk.

In conclusion, we suggest that significantly low changes in LH and FSH levels in nulliparous women can sometimes trigger depression in infertility and subsequently trigger menopause, with detrimental effects on women's health.

\section{ACKNOWLEDGMENTS}

The authors declare that they have no potential conflicts of interest to disclose.

\section{REFERENCES}

1. 1. Arslan AA, Zeleniuch-Jacquotte A, Lukanova A, Afanasyeva Y, Katz J, Levitz M, Del Priore G, Toniolo P. Effects of parity on pregnancy hormonal profiles across ethnic groups with a diverse incidence of breast cancer. Cancer Epidemiol Biomarkers Prev. 2006;15:2123-2130.

2. Brooke H. M., Joseph S.T. Central circadian control of female reproductive function. Frontiers in Endocrinology. 2014; Vol 4, 195: 1-8.

3. Bergfeld, E. G. , Kojima F. N., Cupp A. S., Wehrman M. E., Peters K. E., Mariscal V., et al. Changing dose of progesterone results in sudden changes in frequency of luteinizing hormone pulses and secretion of 17 beta-oestradiol in bovine females. Biol. Reprod. 1996; 54:546-553. 
(2)

4. Cahill, D. J., Wardle P. G., Harlow C. R., Hull M. G. Onset of the preovulatory luteinizing hormone surge: diurnal timing and critical follicular prerequisites. Fertil. Steril. 1998; 70:56-59.

5. Collins, J. S. , Marshall J. C., McCartney C. R. Differential sleep-wake sensitivity of gonadotropin-releasing hormone secretion to progesterone inhibition in early pubertal girls. Neuroendocrinology. 2012; 96:222-227.

6. Frances Fischbach. Effects of the Most Commonly Used Drugs on Frequently Ordered Laboratory Tests. In A Manual of Laboratory and Diagnostic Tests. Lippincott Williams \& Wilkins, USA, 8 Ed., 2009; 1251.

7. Ion Teodorescu Exarcu. Fiziopatologia ovarului. În Fiziologia şi fiziopatologia sistemului endocrin. Editura Medicală, România, Ed. 1989; 1046-1060.

8. Jay S. Mishra, PhD1; Kathirvel Gopalakrishnan, PhD1; Sathish Kumar. Pregnancy Upregulates Angiotensin type 2 Receptor Expression and Increases Blood Flow in Uterine Arteries of Rats. Biol Reprod. 2018; 99(5): 1091-1099.

9. Johnson, M. L., Pipes L., Veldhuis P. P., Farhy L. S., Boyd D. G., Evans W. S. AutoDecon, a deconvolution algorithm for identification and characterization of luteinizing hormone secretory bursts: description and validation using synthetic data. Anal. Biochem. 2008; 381:8-17.

10. Kerdelhue, B. , Brown S., Lenoir V., Queenan J. Jr., Jones G., Scholler R., et al. Timing of initiation of the preovulatory luteinizing hormone surge and its relationship with the circadian cortisol rhythm in the human. Neuroendocrinology. 2002; 75:158-163.

11. Kevin S., Helen S. A woman's prerogative. Nature Neuroscience. 2005; Vol. 8, Nr. 6 : 697-699.

12. Laboratory Corporation of America. Directory of Services and Interpretive Guide. 8. 8.Progesterone. www.labcorp.com 2010. Ref Type: Internet Communication.

13. Liu, J. H., Yen S. Induction of midcycle gonadotropin surge by ovarian steroids in women: a critical evaluation. J. Clin. Endocrinol. Metab. 1983; 57:797-802.

14. Loucks, A. B. , Verdun M., and Heath E. M. Low energy availability, not stress of exercise, alters LH pulsatility in exercising women. J. Appl. Physiol. 1998; 84:37-46.

15. MacLusky, N. J. , McEwen B. S. Oestrogen modulates progestin receptor concentrations in some rat brain regions but not in others. Nature. 1978; 274:276-278.

16. McCartney, C. R. , Blank S. K., Marshall J. C. Progesterone acutely increases LH pulse amplitude but does not acutely influence nocturnal LH pulse frequency slowing during the late follicular phase in women. Am J. Physiol. Endocrinol. Metab. 2007; 292: E900-E906.

17. McCartney, C. R. , Blank S. K., Prendergast K. A., Chhabra S., Eagleson C. A., Helm K. D., et al. Obesity and sex steroid changes across puberty: evidence for marked hyperandrogenemia in pre- and early pubertal obese girls. J. Clin. Endocrinol. Metab. 2007; 92:430-436.

18. McCartney, C. R. , Prendergast K. A., Blank S. K., Helm K. D., Chhabra S., Marshall J. C. Maturation of luteinizing hormone (gonadotropin-releasing hormone) secretion across puberty: evidence for altered regulation in obese peripubertal girls. J. Clin. Endocrinol. Metab. 2009; 94:56-66.

19. Mervaala E, Muller DN, Schmidt F, Park JK, Gross V, Bader M, et al. Blood pressure.

20. Minakami, H. , Kimura K., Yano H., Kanazawa T., Tamada T. The effects of progesterone on gonadotrophin release in hypogonadal women. Acta Endocrinol. (Copenh), 1984; 107:456-461.

21. Pastor, C. L., Griffin-Korf M. L., Aloi J. A., Evans W. S., Marshall J. C. Polycystic ovary syndrome: evidence for reduced sensitivity of the gonadotropin-releasing hormone pulse generator to inhibition by oestradiol and progesterone. J. Clin. Endocrinol. Metab.1998; 83:582-590.

22. Pielecka, Quaynor S. D., Moenter S. M. Androgens increase gonadotropin-releasing hormone neuron firing activity in females and interfere with progesterone negative feedback. Endocrinology. 2006; 147:1474-1479.

23. Robinson, J. E. , Forsdike R. A., Taylor J. A. In utero exposure of female lambs to testosterone reduces the sensitivity of the gonadotropin-releasing hormone neuronal network to inhibition by progesterone. Endocrinology. 1999; 140:5797-5805.

24. Robinson, J. E. , Healey A. E., Harris T. G., Messent E. A., Skinner D. C., Taylor J. A., et al. The negative feedback action of progesterone on luteinizing hormone release is not associated with changes in GnRH mRNA expression in the Ewe. J. Neuroendocrinol.2000; 12:121-129.

25. Sandra M. M., Geschwind I, Bradford I. Plasma LH and FSH during different oestrous cycle conditions in mice. I. Reprod. Fert. 1971; 32: 221-230.

26. Walther Bild, Lucian Hritcu, Cristinel Stefanescu, Alin Ciobica. Inhibition of central Angiotensin II enhances memory function and reduces oxidative stress status in rat hippocampus. Progress in Neuro-Psychopharmacology \& Biological Psychiatry. 2013; 43: 79-88. 
84/Bulletin of Integrative Psychiatry ONew Series O December 2020 ○ Year XXVI ONo. 4 (87)

(1) 27. Ziegler TE. Hormones associated with non-maternal infant care: a review of mammalian and avian studies. Folia Primatol (Basel) 2000;71:6-21.

\section{Correspondence:}

Cristina-Maria Gavrilescu,

Lecturer, MD, PhD, „Grigore T. Popa” University of Medicine and Pharmacy, Iași, Ist Medical Department, Iași, Romania, senior in Internal Medicine, specialist în Geriatrics, specialist în Clinical Pharmacology,cristina.gavrilescu@umfiasi.ro

Submission: 10oct 2020

Acceptance: 02 dec 2020 